\title{
SUICIDE RISK IN ATTENTION-DEFICIT/HYPERACTIVITY DISORDER
}

\author{
Giancarlo Giupponi $^{1}$, Gloria Giordano ${ }^{2}$, Ignazio Maniscalco ${ }^{1}$, Denise Erbuto ${ }^{2}$, Isabella Berardelli ${ }^{2}$, \\ Andreas Conca ${ }^{1}$, David Lester ${ }^{3}$, Paolo Girardi ${ }^{2}$ \& Maurizio Pompili $^{2}$ \\ ${ }^{1}$ Department of Psychiatry, Bolzano, Italy \\ ${ }^{2}$ Department of Neurosciences, Mental Health and Sensory Organs, Suicide Prevention Center, Sant'Andrea Hospital, \\ Sapienza University of Rome, Rome, Italy \\ ${ }^{3}$ The Richard Stockton University, NJ, USA
}

received: 14.6.2017;

revised: 16.1.2018;

accepted: 5.2.2018

\section{SUMMARY}

Background: ADHD (Attention-deficit/hyperactivity disorder) is a common neurodevelopmental disorder that manifests itself during childhood with various combinations of symptoms, including inattention, hyperactivity and impulsivity. Research has shown that psychiatric comorbidities play an important role in the development of suicidal behavior and, recently, there has been a growing interest in a possible association between ADHD and suicide during both childhood and adulthood. Furthermore, some authors have shown a relationship between pharmacological treatments and suicide in patients affected by ADHD.

Aims: We conducted a selective review of current literature to explore the factors which contribute to suicidal behavior and selfharm in those with ADHD.

Methods: We performed a PubMed/MEDLINE, Scopus, PsycLit, and PsycINFO search to identify all articles and book chapters on the topic up to 2017.

Results: Several studies have showed that ADHD may be correlated with an increased suicide ideation and attempts.

Conclusions: Although differences in studies design and samples made the results difficult to compare and interpret, many studies indicate an association between ADHD and suicidal behavior. It remains controversial whether there is a direct relationship or whether the association depends on the increased prevalence of pre-existing comorbid conditions and individual and family dysfunctional factors.

Key words: ADHD - suicide risk - suicide ideation - suicide attempt-adolescence - adulthood

\section{INTRODUCTION}

Suicide is one of the most serious public health problems and represents a frequent cause of medical emergencies with high medical costs (WHO 2014). Suicide is the second leading cause of death among young people aged 15-29 years and the fourth leading cause of death among children aged 5-14 (Hauser et al. 2013, WHO 2014). Several studies have confirmed that self-destruction and suicidal ideation are present in about $10 \%$ of the medical records of adolescent psychiatric inpatients (De Leo et al. 2004, Hargus et al. 2009, Hawton et al. 2002, Hawton et al. 2003, Madge et al. 2008, Moran et al. 2012). Other studies have demonstrated that about $10-15 \%$ of children who present with self-destructive behaviors have a very high risk of completed suicide (Cooper et al. 2005, Hawton et al. 1996, Owens et al. 2002, Spirito et al. 1992). A recent study showed an increasing suicide rate over age in America, going from 0.03 per 100.000 per year among children aged 5-9 and 1.29 among children aged 10-14, to 7.53 among 15- to 19-year-old adolescents and 13.92 among young adults aged 20-29, with the highest rate (16.69) among 40- to 49-year-old adults (Hauser et al. 2013).
ADHD (attention-deficit/hyperactivity disorder) is a common neurodevelopmental disorder characterized by a variable combination of symptoms, including inattention, hyperactivity and impulsivity (Biederman 2005, Biederman et al. 2010, Greydanus et al. 2007, Polanczyk et al. 2007). ADHD symptoms arise during childhood, but can often persist into adulthood in 1079\% of child patients (Biederman et al. 1996, Cantwell 1996, Mannuzza et al. 1991, Shaffer 1994, Spencer et al. 1998, Caye et al. 2016). The prevalence of ADHD during childhood is $5-10 \%$ (Faraone et al. 2003), while during adulthood the prevalence is 1-6\% (Wender et al. 2001). Several authors have studied the correlates of ADHD symptoms in adulthood (Greydanus et al. 2007, Lundervold et al. 2011, Sorensen et al. 2011, Yazgan 2007), and it has been found that adult ADHD increases the risk of antisocial behavior, substance abuse, aggressive behavior, social exclusion, social impairment, and low self-esteem (Babinski et al. 2011, Barkley 2008, Biederman et al. 2012, Brook et al. 2013, Lichtenstein et al. 2012, Rasmussen et al. 2000). To confirm these results, a recent trial (Chaim-Avancini et al. 2017) reported the first neurobiological evidence supporting the individual diagnosis of ADHD in adulthood, based on a sample of stimulant-naıve patients. 
Previous research has also demonstrated an association between ADHD and suicide in male adolescents and in male young adults (Gould et al. 1998, Impey 2011, Kelly et al. 2004, James et al. 2004, Lam 2002, Miller et al. 1982, Murphy 2002) and, in addition, an association between ADHD and self-injurious acts and suicidal ideation in female adolescents (Cho et al. 2008, Manor et al. 2010).

This article will focus on the relationship between ADHD and suicidal/parasuicidal events. We conducted a selective review of the medical literature in order to highlight factors which contribute to suicidal behavior and self-harm in those with ADHD.

\section{METHODS}

To provide a comprehensive review of ADHD and suicidal risk, we performed a PubMed/MEDLINE, Scopus, PsycLit, and PsycINFO search to identify all articles and book chapters on the topic up to 2015. We used the following search terms: suicide* AND ADHD, suicide* AND "attention deficit disorder with hyperactivity”, suicide* AND "attention deficit”, suicide* AND hyperactivity, parasuicide* AND ADHD, parasuicide* AND "attention deficit disorder with hyperactivity”, parasuicide* AND "attention deficit”, parasuicide* AND hyperactivity, self-harm AND ADHD”, self-harm AND "attention deficit disorder with hyperactivity”, self-harm AND "attention deficit”, self-harm AND hyperactivity. The reference lists of the articles included in the review were manually checked for relevant studies. All included articles were in English or German.

\section{RESULTS}

ADHD cohort studies have shown that ADHD patients have a higher risk of suicidal ideation, selfinflicted wounds and suicide (Hurtig et al. 2012, James et al. 2004). Two studies have demonstrated that $10 \%$ of adult subjects with ADHD have attempted suicide in the past and that $5 \%$ of them died by suicide or accidents (Goldstein 2002, Schmidt \& Freidson 1990).

In a large longitudinal sample of Swedish families (Ljung et al. 2014), 51,707 individuals met the criteria for ADHD and were studied 23 years later. Among all the probands, 17,349 (33.6\%) had a comorbid disorder. ADHD patients had an increased rate of attempted and completed suicide compared with matched control $(\mathrm{OR}=8.46$ and $\mathrm{OR}=12.22$, respectively), even after adjusting for comorbid psychiatric disorders ( $\mathrm{OR}=3.62$ and $\mathrm{OR}=5.91$ ), in both males and females. The same study showed an increased rate of suicidal behavior also among relatives of ADHD individuals, with an OR of 2.42 for attempted suicide among parents of ADHD probands and 2.28 among the full siblings of probands with ADHD. First-degree relatives of individuals with ADHD reported a higher risk of completed suicide (OR
2.23-2.24) than second-degree relatives ( $\mathrm{OR}=1.51-2.02)$ and third-degree relatives ( $\mathrm{OR}=1.51)$.

Several studies have shown ADHD patients to have several psychiatric comorbidities (Duran et al. 2014, Goldstein 2002, James et al. 2004, Schmidt \& Freidson 1990). A meta-analysis of 6 prospective studies on suicide (James et al. 2004) suggested that ADHD may increase the severity of other psychiatric comorbidities, such as behavior disorders and depression, and may increase the rate of subsequent completed suicide, albeit modestly.

ADHD patients with a combination of major depressive disorder, behavior disorder and substance abuse have a very high rate of subsequent suicidal behavior (attempted and completed), with major depression disorder being the most frequent diagnosis found among ADHD patients with previous suicide attempts (50.7\%), followed by substance abuse (47.4\%), borderline personality disorder (19.2\%), bipolar disorder (15.6\%), and behavior disorders (8.9\%) (Chen et al. 2014). Duran and colleagues (2014) investigated comorbid psychiatric disorders in adult ADHD outpatients and reported major depressive disorder to be the most frequent diagnosis (43\%), followed by generalized anxiety disorder (23\%), and obsessive- compulsive disorder (17\%). The most common behavior problems in these ADHD patients were substance abuse (58.9\%) and attempted suicide (38.5\%). Ruchkin et colleagues (2017) confirmed that comorbidity of ADHD and drug dependence increased risk for suicidal ideation and comorbidity of ADHD and alcohol dependence increased the risk for suicide attempts.

Several studies have reported cognitive impairment (impaired executive functions) in patients with ADHD (Berlin et al. 2003, Scheres et al. 2004, Thorell 2007), and this is associated with non-suicidal self-injurious behavior (Fikke et al. 2010). In a sample of 59 adult patients with ADHD, Dowson et al. (2007) found that patients with a positive clinical history for previous selfinjurious behavior showed a deficit in spatial working memory. Since several executive functions are involved in the regulation of impulse control and emotions, it has been proposed that deficits of executive functions may predict suicide attempts (Barkley et al. 2001, Zelazo et al. 2007).

\section{Suicidal behavior in children and adolescents with ADHD}

Observational studies have indicated an increased suicide risk among young patients with ADHD compared to the general population (Manor et al. 2010, McCarthy et al. 2009), with male gender and the presence of psychiatric comorbidities (especially behavior disorders and depression) being major suicide risk factors (James et al. 2004). Kelly and colleagues (2004) studied 503 adolescents aged 12 to 19 years with alcohol use disorder, and found that the presence of a mood disorder was the strongest predictor of attempted 
suicide, in both boys and girls, and that ADHD increased the risk for attempted suicide_for boys. In a sample of female adolescents, Biederman and colleagues (2008) found that a combination of ADHD and depression was associated with an increased the incidence of suicidal ideation in adolescent and young adult females. Plattner et al. (2007) studied a sample of 319 young prisoners and found that individuals non-lethal suicidal behavior was associated depression, ADHD and social phobia in the boys, but not in the girls. Rucklidge and colleagues (2001) reported higher rate of self-injurious behavior in a sample of 59 ADHD adolescents (24 girls and 35 boys), compared to 48 healthy controls (28 girls and 20 boys).

In order to identify potential predictors of lifetime suicidal behavior (suicidal ideation, suicide gestures, suicide attempts and self-injurious behaviors), Daviss \& Diler (2014) examined a sample of 101 individuals aged 11-18 years and found lifetime trauma exposure, parentchild conflict, ADHD symptoms, psychiatric comorbidities and social impairment played an important role in the development of suicide behaviors in these adolescents.

Manor et al. (2010) gave 23 adolescents admitted to the emergency room for attempted suicide the Schedule for Affective Disorders and Schizophrenia, Present and Lifetime Version (K-SADS-PL), the Strengths and Difficulties Questionnaire (SDQ), the Conners' Rating Scale (CRS) and the Test of Variables of Attention (TOVA). The_authors found that $65 \%$ of the sample was diagnosed with ADHD, 43.5\% with depressive disorders and $39 \%$ with cluster B personality disorders.

In a longitudinal study, Chronis-Toscano and colleagues (2010) showed that children $(n=125)$ diagnosed with ADHD between 4 and 6 years of age, had an increased risk of major depression or dysthymia (hazard ratio or $\mathrm{HR}, 4.32$ ) and suicide attempt (HR, 3.60) up to the age of 18 years, compared to controls. There were marked variations in risk for this outcome among children with ADHD. Only girls were at greater risk for depression and suicide attempts. Maternal depression and concomitant child emotional and behavior problems from 4 to 6 years of age predicted depression and suicidal behavior.

Hurtig et al. (2012), analyzed data from a sample of 457 adolescents included in the Northern Finland Birth Cohort 1986 to which the K-SADS-PL was administered. The authors found that participants with ADHD $(n=104)$ showed a higher incidence of suicidal ideation (57\% versus $28 \%, \mathrm{P}<0.001$ ) and deliberate self-harm (DSH) (69\% versus 32\%, $\mathrm{P}<0.001)$, compared to adolescent probands without ADHD ( $\mathrm{n}=169)$. The association between ADHD-suicidal ideation remained strong after controlling for other several variables. Other contributing factors to suicidal behavior included female gender, childhood emotional and behavioral problems, depression and anxiety, and, specifically for DSH, behavioral disorder and substance abuse.
Early childhood "suicidal cognition and behavior", defined as persistent suicidal thoughts, suicidal plans and suicidal attempts, was associated with ADHD in a recent prospective longitudinal study of 306 children aged 7-12 years (Whalen et al. 2015). In a sample of adolescent patients hospitalized as a result of injuries, Lam (2002, 2005) found that a diagnosis of ADHD was associated with younger age, male gender and low socioeconomic status, as well as injuries resulting from assault and suicidal behavior.

In an Irish study analyzing the prevalence of psychiatric disorders, suicidal ideation and intent and parasuicide in a population of 723 adolescents (aged 12-15 years), in the community Lynch et al. (2006) found that $15.6 \%$ of the total study population met the criteria for a current psychiatric disorder; $3.7 \%$ of the adolescents received a diagnosis of ADHD, while $19.4 \%$ of the sample were judged to be "at risk" for mental health difficulties and 2.4\% presented possible suicidal intent, based on CDI (Children's Depression Inventory) and SDQ (The Strengths and Difficulties Questionnaire) scores. Significant past suicidal ideation was experienced by $1.9 \%$ of the total sample, and $1.5 \%$ of participants had a history of parasuicide. Donath and colleagues (2014) studied a sample of 44,134 students (15 years of age) in order to analyze the role of parenting behavior and parenting styles in the adolescents' suicide attempts. The overall lifetime prevalence of suicide attempt was $9.0 \%$, and the prevalence of suicidal ideation was $39.4 \%$. Donath, et al. reported that authoritative parenting was a protective factor (OR: 0.79) while rejecting-neglecting parenting was a risk factor (OR: 1.63) for suicidal attempts $(p<0.001)$. ADHD, female gender, smoking, binge drinking, absenteeism/truancy, migration background, and parental separation were also found to be significantly related to suicide attempts, with ADHD showing the highest OR after female gender. In a sample of 349 urban children aged 6-9 years with aggressive behaviors, Wyman et al. (2009) found that $10 \%$ of the children with suicidal ideation met the criteria for ADHD versus 5.6\% of the children with no suicidal ideation. A longitudinal study by Hinshaw (2012) analyzed a population of 140 females aged 6 to 12 years with ADHD (93 with a combined type and 47 with the inattentive type), compared to 88 healthy controls. The suicide attempt rate was $22 \%$ for the combined type and $8 \%$ for the inattentive type, whereas the control group had a $6 \%$ rate. In a 13-year longitudinal study, Goldston et al. (2009), analyzing the relationship between suicide attempts and psychiatric comorbidities in a sample of 180 adolescent inpatients, found that $14.3 \%$ of patients at first suicide attempt and $25 \%$ of participants with several suicide attempts met the criteria for ADHD (OR=2.41).

Dickerson Mayes and colleagues (2015) analyzed suicide ideation and attempts in 1,706 children and adolescents (6-18 years of age) with psychiatric disorders and found an overall incidence of suicidal behavior 
(ideation and non-lethal attempts) of $24 \%$. The incidences by diagnosis were bulimia $48 \%$, major depression or anxiety disorder 34\%, oppositional defiant disorder 33\%, ADHD-combined type 22\%, anorexia nervosa $22 \%$, autism $18 \%$, intellectual disability $17 \%$, and ADHD-inattentive type $8 \%$ ), compared to an incidence of $0.5 \%$ in the healthy control group. In a study of 500 adolescents and young adults aged 15-24 years with bipolar disorder and ADHD, Lan et al. (2015) reported that comorbidity with ADHD to increase the likelihood of attempting suicide in patients aged between 15 and 24 years affected by bipolar disorder.

In a study of 29,737 young subjects aged 0 to 21 years, Sheikh and colleagues (2015) found that $14 \%$ of the sample used ADHD medications to attempt suicide and suggested that undiagnosed ADHD may be a potential cause for self-harming behaviors in very young subjects.

\section{Suicidal behavior in ADHD adults}

Huntley and colleagues (2012) studied a sample of 226 psychiatric patients with substance dependence and found that the ADHD incidence was $12.2 \%$. The presence of an ADHD diagnosis was associated with worse social functioning, abuse of alcohol and substances, depression and suicide attempts, with suicide attempts present in $54.5 \%$ in the ADHD group (likelihood ratio of 4.675). Using the MINI (Mini International Neuropsychiatric Interview), Grall-Bronnec et al. (2011) reported a 25\% prevalence of ADHD in patients affected by gambling addiction, with $62.5 \%$ of the comorbid group (ADHD+gambling) showing "suicide risk (the report did not specify how this was assessed) compared to $34.5 \%$ of participants with gambling addiction only. Arias and colleagues (2008) studied the prevalence and the course of psychiatric comorbidities in a population of 1,761 individuals with substance use disorder and found the incidence of ADHD to be $5.22 \%$. Suicidal ideation was present in $66.30 \%$ of the ADHD group, vs. $42.32 \%$ in the nonADHD group ( $\mathrm{OR}=1.57)$. The suicide attempt rate was $40.66 \%$ in the ADHD group vs. $17.50 \%$ in the nonADHD group $(\mathrm{OR}=2.32)$. The self-injury rate was $20.88 \%$ in the ADHD group vs. $6.31 \%$ in the nonADHD group (OR=3.31). Swanson et al. (2014) found that young adult women with a childhood diagnosis of ADHD-combined type, especially if childhood impulsivity was also present, had a higher incidence of prior suicide attempts than did women with ADHD-inattentive type and those in the control group. Furthermore, chronic ADHD was related to a higher incidence of suicidal behavior (self-harm or suicide attempts) compared to transient diagnosis and non-ADHD. Semiz and colleagues (2008) studied a sample of 105 male prisoners with antisocial personality disorder to evaluate the relationship between ADHD and psychopathy using the Hare Psychopathy Checklist-Revised and the Structured Clinical Interview for Axis II Disorders (DSM-III-R), and noting suicidal behavior and a history of social and familiar adversities. An ADHD diagnosis was present in the $65 \%$ of the sample with an overall self-injury behavior rate of $92 \%$ (average onset at age 14.8 \pm 3.5 ). The ADHD group had a rate of self-injury behavior of $94 \%$ and a rate of attempted suicide of $70 \%$ versus rates of $89 \%$ and $43 \%$, respectively, in the non-ADHD group $(\mathrm{OR}=1.06)$. In a multicenter study in 21 countries, Nock et al. (2009) analyzed suicidal behavior among 108,664 adults in the community with ADHD. He calculated the lifetime odds rations for the incidence of suicidal ideation and attempted suicide to be 1.4-1.9 and 1.7, respectively, in developed countries compared to 1.52.8 and 2.2 in developing countries. Tai et al. (2017) in 1,047 military recruits highlighting that depression and quality of life were mediator in the association between ADHD and suicidality.

\section{The Effects of Medications}

In a Swedish register-based cohort study, Chen et al. (2014) found that a total of 7,019 suicide related events (SRE, defined as lifetime suicide attempt and completed suicide) occurred in 37,936 patients with a diagnosis of ADHD followed for 150,721 person years. The study focused on three stimulants (methylphenidate (N06BA04), amphetamine (N06BA01), and dexamphetamine (N06BA02)) and one non-stimulant (atomoxetine (N06BA09)). Among subjects of the sample, 93.9\% received at least one prescription for methylphenidate and $26.1 \%$ received at least one prescription for atomoxetine. The other two stimulants, amphetamine and dexamphetamine, were rarely prescribed. The authors found that drug treatment of ADHD was associated with an increased rate of SRE (hazard ratio 1.31, 95\% confidence interval 1.19 to 1.44$)$. Nevertheless, the withinpatient analysis demonstrated a inverse association between ADHD drug treatment and the rate of SRE (0.89, 0.79 to 1.00$)$. Among stimulant users, a reduced within-patient rate of SRE was observed during the treatment periods $(0.81,0.70$ to 0.94$)$. Among nonstimulant/mixed users, no significantly increased within-patient rate of SRE was observed during nonstimulant treatment periods (0.96, 0.72 to 1.30$)$.

\section{Atomoxetine}

Atomoxetine is a norepinephrine reuptake inhibitor approved for the treatment of ADHD, with some studies reporting increased suicidality in ADHD patients treated with atomoxetine (Reed et al. 2016). In particular, Wooltorton et al. (2005) found an increased rate of suicidal ideation in children treated with atomoxetine, as confirmed by two meta-analyses (by Bangs et al. (2008) and FDA (2005)) of 14 and 12 pediatric clinical trials, demonstrating a statistically significant association between atomoxetine and suicidal ideation and behavior.

A British cohort study of 2,544 patients treated with atomoxetine reported rates of $1 \%$ and $0.9 \%$ for lifetime self-harm behavior and suicidal ideation, respectively, 
and $0.3 \%$ for both suicide attempt and overdose (Davies et al. 2009). Donnelly and colleagues (2009) studied 714 patients treated with atomoxetine for 3 years, and found a suicidal ideation incidence of $1.5 \%$, a suicide attempt incidence of $0.3 \%$ and completed suicide incidence of $0.1 \%$. A retrospective cohort study, (Linden et al. 2016) was conducted to evaluate suicide events in pediatric patients in treatment with atomoxetine compared with stimulants; however, the authors didn't observe a statistically increase in the risk of suicidal events in both groups of patients.

Future studies will also be needed to investigate the possible role of atomoxetine as a kappa-opioid receptor (KOR) partial agonist and subsequent mediator of e hypothalamic pituitary adrenal (HPA) axis hyperactivity as suggested by some previous studies (Fluegge et al. 2016).

\section{Methylphenidate}

Methylphenidate increases dopamine levels by inhibiting the dopamine transporter (DAT) and adenosine monofosfatase c (Kuczenski et al. 1997). Treatment with methylphenidate has been associated with violent behavior, agitation, and depression with suicidal ideation (Hesapcioglu et al. 2013, Ruggiero et al. 2012). More than 30 years ago, Gualtieri et al. (1985) reported a suicide attempt by methylphenidate ingestion by a patient included in a sample of 8 male adults with ADHD (average age 27.3 years) treated with methylphenidate for 3-6 months.

In 2009 a retrospective cohort study of 5,351 children and adolescents treated with methylphenidate or amphetamine (McCarthy et al. 2009) found an increased standardized mortality ratio (SMR) for complete suicide compared to general population (for 11-14 years old subjects 161.91 and for $15-20$ years old subjects 1.84 ).

On the other hand, in the above-mentioned Swedish study (Chen et al. 2014), the use of drug treatment at the population level was associated with a decreased rate (not statistically significant) of SRE among stimulant users (HR 1.02, 95\% CI 0.90 to 1.16). A statistically significant protective effect of stimulants on suicidal behavior (HR 0.81) has also been reported (Chen et al. 2014). The protective effect is probably mediated by the improvement in impulsivity. After the exclusion of any comorbid condition, the association between the rate of SRE and the use of ADHD drug treatment at the population level (hazard ratio 1.24) was largely attenuated. A recent cohort study (Liang et al. 2017) on 84,898 youths less than 18 years old with ADHD diagnosis evaluated if methylphenidate treatment reduces the risk of suicide attempts and if this effect depended by duration of exposure to treatment. The authors found a 59\% suicide attempt risk reduction among ADHD youths prescribed MPH between 90 days to 180 days and a $72 \%$ risk reduction for those with more than 180 days of MPH. In contrast, Man et al. (2017) observed that, in the period immediately before the start of methylphenidate treatment suicide attempts were more frequent and returned to baseline levels during continuation of the treatment.

The efficacy of methylphenidate hydrochloride extended-release chewable tablets (MPH ERCT) was compared with placebo in children with ADHD in a study composed by 6-week, open-label, dose-optimization treatment period followed by a 1-week, randomized, doubleblind, placebo-controlled period (Wigal et al. 2017). Treatment with MPH ERCT showed a safety and tolerability profile similar to that of other MPH ER formulations and the use of MPH ERCT 20-60mg significantly improved ADHD symptoms compared with placebo.

\section{Amphetamines}

Amphetamines are some of the most powerful central nervous system stimulant substances as capable of increasing synaptic amine levels (Madras et al. 2005). They were initially synthesized in Berlin in 1887 (Fleckenstein et al. 2007), and research showed their affinity to all monoaminergic transporters. In particular, the behavioral stimulant effect has been found to be mediated by increasing dopamine levels through the inhibition of the dopamine active transporter (DAT) and Monoamine Oxidase-A and B (Boutrel et al. 2004)

Some studies have suggested that some methylphenidate-resistant individuals may benefit from amphetamines and vice versa (Elia et al. 1990). The only study on this is a retrospective study (McCarthy et al. 2009), based on the UK GPRD (General Practice Research Database) database. In a sample of 5,351 children and adolescents, those who took amphetamines or methylphenidate showed an increased standardized mortality ratio (SMR) for complete suicide compared to the general population. The standardized mortality ratio (SMR) was 161.91 in those 11-14 years old and 1.84 in those 15-20 years old.

\section{CONCLUSIONS}

In this paper, we have reviewed research about the relationship between ADHD and suicidal behavior in children, adolescents and adults. Differences in study design (cross-sectional vs. longitudinal, population-based vs. case-control) and samples made the results difficult to compare and interpret. Nevertheless, many studies indicate an association between ADHD and suicidal behavior, but it is still controversial whether there is a direct relationship or whether the association depends on the increased prevalence of pre-existing comorbid conditions and individual and family dysfunctional factors. Regardless, patients with ADHD should be routinely screened for suicidal behavior, and early intervention protocols should be established in order to detect and reduce suicidal ideation and behavior and to improve the quality of life. Clinician should pay attention if, apart from the features of the primary disorder, symptoms ascribed to mixed states, especially when depression escalates into mania and when volatile and 
erratic moods are associated with dysphoria and agitation, are detectable in patients. Doctors and caretakers should also bear in mind characteristics of the "Is Path Warm?” indicating warning signs for suicide such as Ideation - threatened or communicated; Substance abuse - excessive or increased; Purposeless - no reasons for living; anhedonia; Anxiety - agitation/insomnia; Trapped - feeling no way out; perceived burdensomeness; Hopelessness; Withdrawal - from friends, family, society; Anger (uncontrolled)/rage/seeking revenge; Recklessness - risky acts; unthinking; Mood changes (dramatic).

In conclusion, more research is needed to better understand the role of ADHD in suicidal behavior during childhood, adolescence and adulthood and to identify risk factors for future suicidal behavior in this population in order to develop prevention programs and improve treatment approaches. Furthermore, more research is needed on whether the medication prescribed for ADHD patients are effective in reducing the incidence of suicidal behavior.

\section{Acknowledgements: None.}

Conflict of interest: None to declare.

\section{Contribution of individual authors:}

Giancarlo Giupponi designed the study;

Giancarlo Giupponi, Gloria Giordano \& Ignazio Maniscalco reviewed the study;

Denise Erbuto, Isabella Berardelli \& Andreas Conca supervised the study;

David Lester contributed in drafting the paper and in providing consultancy for pending papers to be included;

Paolo Girardi \& Maurizio Pompili provided the scientific impetuous for the study. All authors contributed in drafting the paper.

\section{References}

1. Arias AJ, Gelernter J, Chan G, Weiss RD, Brady K, Farrer L, et al.: Correlates of co-occurring ADHD in drug-dependent subjects: prevalence and features of substance dependence and psychiatric disorders. Addict Beha 2008; 33:1199-207

2. Babinski DE, Pelham WE, Molina BSG, Gnagy EM, Wasch-Busch, et al.: Late adolescent and young adult outcomes of girls diagnosed with ADHD in childhood: an exploratory investigation. Journal attent disord 2011; 15:204-214

3. Bangs ME, Tauscher-Wisniewski S, Polzer J, Zhang S, Acharya N, Desaiah D et al.: Meta-analysis of suiciderelated behavior events in patients treated with atomoxetine. J Am Acad Child Adolesc Psychiatry 2008; 47:209-18

4. Barkley RA: The executive functions and self-regulation: An evolutionary neuropsychological perspective. Neuropsyc review 2001; 11:1-29
5. Barkle RA: Global issues related to the impact of untreated attention-deficit/hyperactivity disorder from childhood to young adulthood. Postgrad Med 2008; 120:48-59

6. Berlin L, Bohlin G, Rydell A: Relations between inhibition, executive functioning, and ADHD symptoms: $A$ longitudinal study from age 5 to 8 1/2 years. Child Neuropsy 2003; 9:255-266

7. Biedermann, J, Faraone S, Millberger S, Guite J, Mick E, Chen L, et al.: A Prospective 4-year Follow-up Study of Attention Deficit Hyperactivity and Related Disorders. Arch gen psychiatry 1996; 53:437-46

8. Biederman J: Attention-deficit/hyperactivity disorder: a selective overview. Biol Psychiatry 2005; 57:1215-20

9. Biederman J, Ball SW, Monuteaux MC, Mick E, Spencer TJ, McCreary et al.: New insights into the comorbidity between ADHD and major depression in adolescent and young adult females. J Am Acad Child Adolesc Psychiatry 2008; 47:426-434

10. Biederman J, Petty CR, Monuteaux M, Fried R, Byrne D, Mirto $T$ et al.: Adult psychiatric outcomes of girls with attention deficit hyperactivity disorder: 11-year follow-up in a longitudinal case-control study. Am J Psychiatry 2010; 167:409-17

11. Biederman J, Petty CR, Woodworth K, Lomedico A, Hyder LL, Faraone SV: Adult outcome of attention-deficit/hyperactivity disorder: a controlled 16-year follow-up study. J Clin Psychiatry 2012; 7:941-950

12. Boutrel, B, Koob GF: What keeps us awake: the neuropharmacology of stimulants and wakefulness-promoting medications. Sleep 2004; 27:1181-1194

13. Brook JS, Brook DW, Zhang C, Seltzer N, Finch SJ: Adolescent ADHD and adult physical and mental health, work performance, and financial stress. Pediatrics 2013; 131:5-13

14. Caye A, Rocha TB, Anselmi L, Murray J, Menezes AM, Barros FC et al.: Attention-Deficit/Hyperactivity Disorder Trajectories From Childhood to Young Adulthood: Evidence From a Birth Cohort Supporting a Late-Onset Syndrome. JAMA Psychiatry 2016; 73:705-12

15. Cantwell DP: Attention Deficit Disorder: A Rewiev of the Past 10 Years. J Am Acad Child Adolesc Psychiatry 1996; 35:978-87

16. Chaim-Avancini TM, Doshi J, Zanetti MV, Erus G, Silva MA, Duran FLS et al.: Neurobiological support to the diagnosis of ADHD in stimulant-naïve adults: pattern recognition analyses of MRI data. Acta Psychiatrica Scandinavica 2017; 136:623-636

17. Chen Q, Sjölander A, Runeson B, D'Onofrio BM, Lichtenstein P, Larsson H: Drug treatment for attention-deficit/ hyperactivity disorder and suicidal behaviour: register based study. BMJ 2014; 348:g3769

18. Cho SC, Kim J, Choi HJ, Kim BN, Shin MS, Lee JH et al.: Associations between symptoms of attention deficit hyperactivity disorder, depression, and suicide in Korean female adolescents. Depress Anxiety 2008; 25:142-146

19. Chronis-Tuscano, A, Molina BSG, Pelham WE, Applegate $B$, Dahlke A, Overmeyer $M$ et al.: Very early predictors of adolescent depression and suicide attempts in children with attention-deficit/hyperactivity disorder. Arch Gen Psychiatry 2010; 67:1044-1051

20. Cooper J, Kapur N, Webb R, Lawlor M, Guthrie E, Mackway-Jones K, Appleby L: Suicide after deliberate self-harm: a 4-Year Cohort Study. Am J Psychiatry 2005; 162:297-303 
21. Davies M, Cornelius V, Fogg C, Wilton L, Shakir S: A study to examine events of suicidal ideation in patients prescribed atomoxetine in England. Drug Saf 2009; 32:976

22. Daviss WB \& Diler RS: Suicidal behaviors in adolescents with ADHD: associations with depressive and other comorbidity, parent-child conflict, trauma exposure, and impairment. J Atten Disord 2014; 18:680-90

23. De Leo D, Heller TS: Who are the kids who self-harm? An Australian self-report school survey. Med J Aust 2004; 181:140-144

24. Dickerson Mayes S, Calhoun SL, Baweja R, Mahr F: Suicide ideation and attempts in children with psychiatric disorders and typical development. Crisis 2015; 36:55-60

25. Donath C, Graessel E, Baier D, Bleich S, Hillemacher T: Is parenting style a predictor of suicide attempts in a representative sample of adolescents? BMC Pediatrics 2014; 14:113

26. Donnelly C, Bangs $M$, Trzepacz P, Jin L, Zhang S, Witte $M M$ et al.: Safety and tolerability of atomoxetine over 3 to 4 years in children and adolescents with ADHD. $J$ Am Acad Child Adolesc Psychiatry 2009; 48:176-185

27. Dowson, JH, Blackwell AD, Turner DC, Harvey E, Malhotra T, Robbins TW et al.: Questionnaire ratings of attention-deficit/hyperactivity disorder (ADHD) in adults are associated with spatial working memory. Eur Psychiatry 2007; 22:256-263

28. Duran S, Fistikci N, Keyvan A, Bilici M, Callşkan M: ADHD in Adult Psychiatric Outpatients: Prevalence and Comorbidity. Türk psikiyatri dergisi 2015; 25:84-93

29. Elia J, Borcherding BG, Potter WZ, Mefford IN, Rapoport $J L$, Keysor CS: Stimulant drug treatment of hyperactivity: biochemical correlates. Clin Pharmacol Ther 1990; 48:57-66

30. Faraone SV, Sergeant J, Gillberg C, et al.: The worldwide prevalence of ADHD: is it an American condition? World Psychiatry 2003; 2:104-13

31. Fikke, LT, Melinder A, Landro NI: Executive functions are impaired in adolescents engaging in non-suicidal selfinjury. Psychol Med 2010; 41:601-610

32. Fleckenstein AE, Volz TJ, Riddle EL, Gibb JW, Hanson GR: New insights into the mechanism of action of amphetamines. Annu Rev Pharmacol Toxicol 2007; 47:681-698

33. Fluegge K: Atomoxetine, $A D H D$, and the ongoing debate about increased risk of suicidal behaviors: the understudied role of kappa opioid receptor agonism Response to: Capuano A, Scavone C, Rafaniello C, et al. (2016). Atomoxetine in the treatment of attention deficit hyperactivity disorder and suicidal ideation. Expert Opin Drug Saf. 2014;13 Suppl 1:S69-78. Expert Opinion on Drug Safety; Aug; 15:1147

34. Food and Drug Administration: Public health advisory: suicidal thinking in children and adolescents being treated with Strattera (atomoxetine) 2005; FDA

35. Goldstein S: Continuity of ADHD in Adulthood: Hypothesis and Theory Meet Realty. In: Goldstein S. \& Ellison AT. (Eds), Clinican's to Adult ADHD Assesment and Intervention. California, USA: Academic Pres 2002

36. Goldston, DB, Daniel SS, Erkanli A, Reboussi, BA, Mayfield A, Frazier PH, Treadway S: Psychiatric diagnoses as contemporaneous risk factors for suicide attempts among adolescents and young adults: developmental changes. $J$ Consult Clin Psychol 2009: 77:281-90
37. Gould MS, King R, Greenwald S, Fisher P, Schwab-Stone $M$, Kramer R. et al.: Psychopathology associated with suicidal ideation and attempts among children and adolescents. J Am Acad Child Adolesc Psychiatry 1998; 37:915-923

38. Grall-Bronnec M, Wainstein L, Augy J, Bouju G, Feuillet $F$, Vénisse JL et al.: Attention deficit hyperactivity disorder among pathological and at-risk gamblers seeking treatment: a hidden disorder. Eur Addict Res 2009; 17:231-40

39. Greydanus DE, Pratt HD, Patel DR: Attention deficit hyperactivity disorder across the lifespan: the child, adolescent, and adult. Disease-a-month 2009; 53:70-131

40. Gualtieri CT, Ondrusek MG, Finley C: Attention Deficit Disorder in Adults. Clin neuropharm 1985; 8:343-356

41. Hargus E, Hawton K, Rodham K: Distinguishing between subgroups of adolescents who self-harm. Suicide Life Threat Behav 2009; 39:518-537

42. Hauser M, Galling B, Correll CU: Suicidal ideation and suicide attempts in children and adolescents with bipolar disorder: a systematic review of prevalence and incidence rates, correlates, and targeted interventions. Bip Dis 2013; 15:507-523

43. Hawton K, Fagg J, Simkin S: Deliberate self-poisoning and self injury in children and adolescents under 16 years of age in Oxford, 1976-1993. Br J Psychiatry 1996; 169:202-208

44. Hawton, K, Rodham K, Evans E, Weatherall R: Deliberate self-harm in adolescents: self report survey in schools in England. Br J Psychiatry 2002; 325:1207-1211

45. Hawton K, Hall S, Simkin S, Bale L, Bond A, Codd S, Stewart A: Deliberate self-harm in adolescents: a study of characteristics and trends in Oxford, 1990-2000. J Child Psychol Psychiatry 2003; 44:1191-1198

46. Hesapcioglu ST, Goker Z, Bilginer C, Kandil S: Methylphenidate induced psychotic symptoms: Two cases report. J Med Case Rep 2013; 4:106-8

47. Hinshaw SP, Owens EB, Zalecki C, Huggins SP, Montenegro-Nevado AJ, Schrodek et al.: Prospective follow-up of girls with attention-deficit/hyperactivity disorder into early adulthood: continuing impairment includes elevated risk for suicide attempts and self-injury. J Consult Clin Psychol 2012; 80:1041-1051

48. Huntley Z, Maltezos $S$, Williams $C$, Morinan A, Hammon $A$, Ball, D. et al.: Rates of undiagnosed attention deficit hyperactivity disorder in London drug and alcohol detoxification units. BMC Psychiatry 2012; 12:223

49. Hurtig T, Taanila A, Moilanen I, Nordström T, Ebeling H: Suicidal and self-harm behaviour associated with adolescent attention deficit hyperactivity disorder. A study in the Northern Finland Birth Cohort 1986. Nord J Psychiatry 2012; 66:320-328

50. Impey M: Completed suicide, ideation and attempts in Attention Deficit Hyperactivity Disorder. Acta Psychiatr Scand 2011; 125:93-102

51. Liang SH, Yang YH, Kuo TY, Liao YT, Lin TC, Lee Y et al.: Suicide risk reduction in youths with attentiondeficit/hyperactivity disorder prescribed methylphenidate: A Taiwan nationwide population-based cohort study. Int Rev Res Dev Disabil 2017; 72:96-105

52. Linden S, Bussing R, Kubilis P, Gerhard T, Segal R, Shuster JJ et al.: Risk of Suicidal Events With Atomoxetine Compared to Stimulant Treatment: A Cohort Study. Pediatr 2016; 137 
53. James A, Lai FH, Dahl C.: Attention deficit hyperactivity disorder and suicide: a review of possible associations. Acta Psychiatr Scand 2004; 110:408-415

54. Kelly TM, Cornelius JR, Clark DB: Psychiatric disorders and attempted suicide among adolescents with substance use disorders. Drug Alcohol Depend 2004; 73:87-97

55. Kuczenski R, Segal DS: Effects of methylphenidate on extracellular dopamine, serotonin, and norepinephrine: Comparison with amphetamine. J Neurochem 1997; 68:2032-7

56. Lam LT: Attention deficit disorder and hospitalization due to injury among older adolescents in New South Wales, Australia. J Atten Disord 2002; 6:277-282

57. Lam LT: Attention deficit disorder and hospitalization owing to intra-and interpersonal violence among children and young adolescents. J Adolesc Health 2005; 36:19-24

58. Lan WH, Bai YM, Hsu JW, Huang KL, Su TP, Li CT et al.: Comorbidity of $A D H D$ and suicide attempts among adolescents and young adults with bipolar disorder: A nationwide longitudinal study. J Affect Disord 2015; 1:171-5

59. Lichtenstein P, Halldner L, Zetterqvist J, Sjölander A, Serlachius E, Fazel S. et al.: Medication for attention deficit-hyperactivity disorder and criminality. $N$ Engl $J$ Med 2012; 367:2006-2014

60. Ljung T, Chen Q, Lichtenstein P, Larsson H: Common etiological factors of attention-deficit/hyperactivity disorder and suicidal behavior: a population-based study in Sweden. JAMA Psychiatry 2014; 71:958-64

61. Lundervold AJ, Adolfsdottir S, Halleland H, Halmoy A Plessen KJ, Haavik J: Attention network test in adults with ADHD-the impact of affective fluctuations. Behav Brain Funct 2011; 7:27

62. Lynch F, Mills C, Daly I, Fitzpatrick C: Challenging times: prevalence of psychiatric disorders and suicidal behaviours in Irish adolescents. J Adolesc 2006; 29:555-573

63. Madge N, Hewitt A, Hawton K, Wilde EJD, Corcoran, P., Fekete, $S$. et al.. Deliberate self-harm within an international community sample of young people: comparative findings from the Child and Adolescent Self-harm in Europe (CASE) Study. J Child Psychol Psychiatry 2008; 49:667-677

64. Madras BK, Miller GM, Fischman AJ: The dopamine transporter and attention-deficit/hyperactivity disorder. Biol psych 2005; 57:1397-1409

65. Mannuzza S, Kleine G, Bonagura N, Malloy P Giampino TL, Addalli KA: Hyperactive Boys Almost Grown up, II: Status of Subjects Without a Mental Disorder. Arch gen psych 1991; 48:77-83

66. Man KKC, Coghill D, Chan EW, Lau WCY, Hollis C, Liddle E., et al.: Association of Risk of Suicide Attempts With Methylphenidate Treatment. JAMA Psychiatry 2017; 74:1048-1055

67. Manor I, Gutnik I, Ben-Dor DH, Apter A, Sever J, Tyano S et al.: Possible association between attention deficit hyperactivity disorder and attempted suicide in adolescents - a pilot study. Eur Psychiatry 2010; 25:146-150

68. McCarthy S, Cranswick N, Potts L, Taylor E, Wong IC: Mortality associated with attention-deficit hyperactivity disorder (ADHD) drug treatment: a retrospective cohort study of children, adolescents and young adults using the general practice research database. Drug Saf 2009; $32: 1089-96$
69. Miller M, Chiles J, Barnes V: Suicide attempters within a delinquent population. Journal of consulting and clinical psychology 1982; 50:491-498

70. Moran P, Coffey C, Romaniuk H, Olsson C, Borschmann $R$, Carlin JB. et al.: The natural history of self-harm from adolescence to young adulthood: a population-based cohort study. Lancet 2012; 379:236-243

71. Murphy KR, Barkley RA, Bush T: Young adults with attention deficit hyperactivity disorder: subtype differences in comorbidity, educational and clinical history. J Nerv Ment Dis 2002; 190:147-157

72. Nock MK, Hwang I, Sampson N, Kessler RC, Angermeyer $M$, Beautrais A et al.: Cross-National Analysis of the Associations among Mental Disorders and Suicidal Behavior: Findings from the WHO World Mental Health Surveys. PLoS Med 2009; 6:e1000123

73. Owens D, Horrocks J, House A: Fatal and non-fatal repetition of self-harm: systematic review. $\mathrm{Br} J$ Psychiatry 2002; 181:193-199

74. Plattner B, The SS, Kraemer HC, Williams RP, Bauer SM, Kindler J. et al.: Suicidality, psychopathology, and gender in incarcerated adolescents in Austria. J Clin Psychiatry 2007; 68:1593-1600

75. Polanczyk, G, de Lima MS, Horta BL, Biederman J, Rohde LA: The worldwide prevalence of ADHD: a systematic review and metaregression analysis. Am $J$ Psychiatry 2007; 164:942-8

76. Rasmussen P, Gillberg C: Natural outcome of ADHD with developmental coordination disorder at age 22 years: a controlled, longitudinal, community-based study. J Am Acad Child Adolesc Psychiatry 2000; 39:1424-1431

77. Reed VA, Buitelaar JK, Anand E, Day KA, Treuer T, Upadhyayam HP et al.: The Safety of Atomoxetine for the Treatment of Children and Adolescents with Attention-Deficit/Hyperactivity Disorder: A Comprehensive Review of Over a Decade of Research. CNS Drugs 2016; 30:603-28

78. Rucklidge JJ, Tannock R: Psychiatric, psychosocial, and cognitive functioning of female adolescents with ADHD. $J$ Am Acad Child Adolesc Psychiatry 2001; 40:530-540

79. Ruchkin V, Koposov RA, Koyanagi A, Stickley A: Suicidal Behavior in Juvenile Delinquents: The Role of ADHD and Other Comorbid Psychiatric Disorders. Child Psychiatry Hum Dev 2016

80. Ruggiero S, Rafaniello C, Bravaccio C, Grimaldi G, Granato $R$, Pascotto, A. et al.: Safety of attention-deficit/ hyperactivity disorder medications in children: An intensive pharmaco-surveillance monitoring study. J Child Adolesc Psychopharmacol 2012; 22:415-22

81. Scheres A, Oosterlaan J, Geurts H, Morein-Zamir S, Meiran N, Schut $H$ et al.: Executive functioning in boys with ADHD: Primarily an inhibition deficit? Arch Clin Neuropsychol 2004; 19:569-594

82. Schmidt $K \&$ Freidson S: Atypical Outcome in Attention Deficit Hyperactivity Disorder. J Am Acad Child Adolesc Psychiatry 1990; 29:566-70

83. Semiz UB, Basoglu C, Oner O, Munir KM, Ates A, Algul A et al.: Effects of diagnostic comorbidity and dimensional symptoms of attention-deficit-hyperactivity disorder in men with antisocial personality disorder. Aust NZJ Psychiatry 2008; 42:405-13

84. Shaffer D: Attention Deficit Hyperactiviity Disorder in Adults. Am J Psychiatry 1994; 44:260-8 
85. Sheikh S, Hendry P, Lynch S, Kalynych CJ, Aldridge P, Kraemer D: Poisonings with Suicidal Intent Aged 0-21 Years Reported to Poison Centers 2003-12. West J Emerg Med 2015; 16:497-502

86. Sorensen L, Plessen KJ, Nicholas J, Lundervold AJ: Is behavioral regulation in children with ADHD aggravated by comorbid anxiety disorder? J Atten Disord 2011; 15:56-66

87. Spencer TJ, Biedermann J, Wilens T, Faraone SV: Adults with Attention Deficit/Hyperactivity Disorder: A Controversial Diagnoses. J Clin Psychiatry 1998; 59:59-68

88. Spirito A, Plummer B, Gispert M, Levy S, Kurkjian J, Lewander $W$ et al.: Adolescent suicide attempts: outcomes at follow-up. Am J Orthopsychiatry 1992; 62:464-468

89. Swanson EN, Owens EB, Hinshaw SP: Pathways to selfharmful behaviors in young women with and without ADHD: a longitudinal examination of mediating factors. $J$ Child Psychol Psychiatry 2014; 55:505-15

90. Tai YM, Gau SS: Depression and Quality of Life Mediating the Association Between Attention Deficit/Hyperactivity Disorder and Suicidality in Military Recruits. Mil Med 2017; 182:e1912-e1919

91. Thorell LB: Do delay aversion and executive function deficits make distinct contributions to the functional impact of ADHD symptoms? A study of early academic skill deficits. J Child Psychol Psychiatry 2007; 48:1061-1070

92. Wender P, Wolf L, Wassertein J: Adults with ADHD: An overview. Ann N Y Acad Sci 2001; 931:1-16
93. Whalen DJ, Dixon-Gordon K, Belden AC, Barch D, Luby $J L$ : Correlates and Consequences of Suicidal Cognitions and Behaviors in Children Ages 3 to 7 Years. J Child Psychol Psychiatry 2015; 54: 926-37

94. WHO: Suicide Prevention in Europe. The WHO European monitoring survey on national suicide prevention programmes and strategies 2002. Copenhagen, 1-24

95. Wigal SB, Childress A, Berry SA, Belden H, Walters F, Chappell $P$ et al.: Efficacy and Safety of a Chewable Methylphenidate Extended-Release Tablet in Children with Attention-Deficit/Hyperactivity Disorder. J Am Acad Child Adolesc Psychiatry 2017; 27:690

96. Wooltorton E: Suicidal ideation among children taking atomoxetine (Strattera). Can Med Assoc J 2005; 173:1447-1447

97. Wyman PA, Gaudieri PA, Schmeelk-Cone K, Cross W, Brown CH, Sworts L. et al.: Emotional triggers and psychopathology associated with suicidal ideation in urban children with elevated aggressive-disruptive behavior. J Abnorm Child Psychol 2009; 37:917-28

98. Yazgan Y: Attention Deficit Hyperactivity Syndrome when the Hyperactive children grow up (adulthood). Turkiye Klinikleri J Pediatr Sci 2007; 3:45-55

99. Zelazo PD. \& Cunningham, W.A. Executive function: Mechanisms underlying emotion regulation. In: Gross JJ (eds). Handbook of emotion regulation (pp: 135-158.) 2007. New York, NY: Guilford Press

Correspondence:

Maurizio Pompili, MD, PhD

Department of Neurosciences, Sant'Andrea Hospital, Sapienza University of Rome

Via di Grottarossa 1035, 00189 Rome, Italy

E-mail:maurizio.pompili@uniroma1.it 